\title{
AVALIAÇÃO ECONÔMICA DO USO DA MADEIRA DE EUCALIPTO PARA DIFERENTES FINALIDADES, NA REGIÃO DO ALTO JEQUITINHONHA, MG
}

\author{
Rogger Miranda Coelho ${ }^{1 *}$, Ângelo Márcio Pinto Leite ${ }^{1}$, Marcelino Serretti Leonel ${ }^{2}$, José Jhones Matuda ${ }^{1}$ \\ Luis Carlos Freitas ${ }^{3}$
${ }^{1}$ Universidade Federal dos Vales do Jequitinhonha e Mucuri, Programa de Pós-Graduação em Engenharia Florestal, Diamantina, Minas Gerais, Brasil -roggermcoelho@yahoo.com.br*; ampleite@ig.com.br; jjmatuda@yahoo.com.br
${ }^{2}$ Universidade Federal dos Vales do Jequitinhonha e Mucuri, Instituto de Ciência e Tecnologia, Diamantina, Minas Gerais, Brasil - \\ ${ }^{3}$ Universidade Estadual do Sudoeste da Bahia, Vitória da Conquista, Bahia, Brasil - luiscarlos_ufv@yahoo.com.br
}

Recebido para publicação: 18/11/2014 - Aceito para publicação: 29/03/2016

\begin{abstract}
Resumo
Objetivou-se com esta pesquisa avaliar a viabilidade econômica do uso da madeira de eucalipto para quatro finalidades distintas, a saber: carvão vegetal, energia/lenha, construção civil e serraria, proveniente de plantios em propriedades rurais da região do Alto Vale do Jequitinhonha, MG. Procedeu-se a análise econômica utilizando-se os três métodos de avaliação de projetos mais comumente empregados no Brasil, uma vez estes considerarem a variação do capital no tempo, a saber: Valor Presente Líquido (VPL), Valor Periódico Equivalente (VPE) e Taxa Interna de Retorno (TIR). Realizou-se uma análise de sensibilidade considerando-se as três taxas de juros mais utilizadas em avaliações econômicas de projetos florestais de $6 \%, 9 \%$ e $12 \%$ ao ano (a.a), considerando-se também variação na produção e no preço da madeira de $10 \%$ (ambas para mais e para menos). $\mathrm{O}$ uso da madeira que proporcionou maior retorno financeiro considerando a taxa anual de desconto de $6 \%$ foi a produção de madeira para construção civil (VPL=R $\$ 16.965,38 / \mathrm{ha}$; VPE=R $\$ 1.825,22 / \mathrm{ha} / \mathrm{ano}$; $\mathrm{TIR}=38,0 \%$ ). Por sua vez, para esta mesma taxa de juros a madeira em tora destinada a produção de energia / lenha gerou a menor rentabilidade (VPL=R $\$ 402,66 /$ ha; $\mathrm{VPE}=\mathrm{R} \$ 43,32 / \mathrm{ha} / \mathrm{ano}$; $\mathrm{TIR}=8,0 \%$ ), tornando-se este uso inviável economicamente para as taxas de desconto de $9 \%$ e $12 \%$ a.a.

Palavras-chave: Silvicultura; viabilidade econômica; projetos florestais.
\end{abstract}

\begin{abstract}
Economic evaluation of Eucalyptus wood use for different purposes in the region of Alto Jequitinhonha, MG. The objective of this research was to evaluate the economic viability of Eucalyptus wood use for four different purposes: charcoal, energy/firewood, construction and sawmill. We performed economic analysis using the three methods of project evaluation most commonly employed in Brazil, since they consider the capital variation in time, known as: Net Present Value (NPV), Equivalent Periodic Value (EPV) and Internal Rate of Return (IRR). We also performed a sensitivity analysis, considering the three rates most used in economic evaluation of forest projects, $6 \%, 9 \%$ and $12 \%$ per year (p.y.), also considering variation in production and in $10 \%$ of wood prices (both for more and less). The wood use that provided the greatest financial return considering discount rate of $6 \%$, was the production of wood for construction (NPV $=\mathrm{R} \$$ $16,965.38 /$ ha; $\mathrm{EPV}=\mathrm{R} \$ 1,825.22 /$ ha/year; $\mathrm{IRR}=38.0 \%$ ). For such interest rate, the production of $\operatorname{logs}$ destined for energy/firewood generated lower profitability (NPV $=\mathrm{R} \$ 402.66 / \mathrm{ha}$; EPV= R \$ 43.32/ha/year; $\operatorname{IRR}=8.0 \%$ ), use that is uneconomical for the discount rates of $9 \%$ and $12 \%$ (p.y.).

Keywords: Silviculture; economic viability; forestry projects.
\end{abstract}

\section{INTRODUÇÃO}

O Alto Vale do Jequitinhonha esta localizado na porção nordeste do estado de Minas Gerais, situandose entre a nascente do rio Jequitinhonha no município do Serro e, a foz do rio Araçuaí. Esta região é marcada historicamente pelo baixo dinamismo econômico, sendo denominada desde 1960 como "região problema" ou um "bolsão de pobreza" (CALIXTO; RIBEIRO, 2007).

Apesar dos problemas sociais agravados pelo clima semiárido, o Alto Vale do Jequitinhonha se destaca nacionalmente na atividade de reflorestamento com eucalipto, tendo sido implantado os primeiros maciços florestais na região a partir da década de 70 , em virtude da disponibilidade de mão de obra, baixo preço das terras e, benefícios da política de incentivos fiscais concedidos pelo governo federal, por intermédio da Lei 5.106/1966 (SOUZA, 2012; CHAVES; RIBEIRO, 2014).

A facilidade de mecanização favorecida pelo relevo plano da região (chapadas) e de aquisição de terras

FLORESTA, Curitiba, PR, v. 46, n. 2, p. 155 - 164, abr. / jun. 2016.

Coelho, R. M. et al.

ISSN eletrônico 1982-4688

DOI: $10.5380 /$ rf.v46i2.38600 
adequadas a projetos florestais em detrimento à agricultura favoreceu a consolidação de distritos florestais no Alto Jequitinhonha, principalmente por parte de grandes empresas, proporcionando uma grande expansão da cultura do eucalipto na região (CALIXTO et al., 2009).

O estabelecimento de plantios de eucalipto em larga escala na região trouxe consigo impactos negativos, sobretudo na estrutura fundiária, resultando na formação de latifúndios pelas empresas reflorestadoras. Segundo Oliveira et al. (2006), a formação de latifúndios no setor florestal poderia ser mitigada caso as políticas de incentivos fiscais fossem associadas a subsídios para produtores rurais, por meio do fomento florestal, contingenciando desta maneira, o processo de concentração de terras.

Embora a ocupação territorial do Vale do Jequitinhonha tenha resultado em grandes monocultivos de eucalipto, nos últimos anos, aumenta cada vez mais os plantios florestais com essa espécie por parte de produtores rurais, que têm visto nesta atividade uma fonte de renda alternativa aos projetos agropecuários. Cabe ressaltar que, a inserção de pequenos e médios produtores na atividade florestal é de fundamental importância na garantia do desenvolvimento socioeconômico das comunidades locais, melhorias na qualidade de vida da população, bem como na promoção da sustentabilidade dos empreendimentos florestais e industriais (SOUZA et al., 2009; CORDEIRO et al., 2010).

Apesar da grande importância desta atividade na região, estudos que tratam da viabilidade econômica da produção de madeira de eucalipto em pequenas propriedades rurais são escassos, particularmente quais usos correspondem às melhores alternativas de investimento. Neste contexto que, objetivou-se com esta pesquisa analisar a viabilidade econômica da produção de madeira de eucalipto para quatro diferentes usos da madeira, proveniente de produtores rurais da região do Alto Vale do Jequitinhonha, utilizando-se os métodos de avaliação econômica de projetos: Valor Presente Líquido (VPL), Valor Periódico Equivalente (VPE) e, Taxa Interna de Retorno (TIR).

\section{MATERIAIS E MÉTODOS}

\section{Área de estudo}

Realizou-se esta pesquisa perante produtores rurais dos municípios do Alto Vale do Jequitinhonha, MG, a saber: Gouveia, Datas, Diamantina, Carbonita, Itamarandiba, Turmalina, Minas Novas e Angelândia.

Localizada entre os paralelos $17^{\circ}$ e $18^{\circ}$ e os meridianos $41^{\circ}$ e $42^{\circ}$, a região caracteriza-se pela predominância de latossolos distróficos, com variação pluviométrica anual compreendida entre 600 e $1.600 \mathrm{~mm}$ irregularmente distribuídos ao longo do ano (SOUZA et al., 2012). A temperatura média anual varia de 21 a $24^{\circ} \mathrm{C}$, com evapotranspiração situando-se na faixa dos 800 a mais de $1200 \mathrm{~mm}$ (GONÇALVES, 1997).

\section{Coleta de dados}

Realizou-se inicialmente um levantamento prévio dos produtores rurais detentores de povoamentos de eucalipto que já haviam realizado pelo menos um corte destes, consultando-se a Empresa de Assistência Técnica e Extensão Rural do Estado de Minas Gerais (EMATER-MG) e, o Instituto Estadual de Florestas (IEF-MG). Posteriormente, quando da ida a campo nos municípios selecionados identificou-se outros produtores rurais que eram detentores de plantios de eucalipto e já haviam cortado e comercializado madeira dessa espécie mediante informações de terceiros, para proceder-se a coleta de dados (aplicação de questionário estruturado in loco), por intermédio de amostragem aleatória.

O questionário continha questões abertas e fechadas abordando características das propriedades tais como: área total, área com reflorestamento perspectivas de plantio de florestas, custos e receitas provenientes dos reflorestamentos, comercialização e preços de produtos e subprodutos florestais, tendo sido este aplicado em julho de 2011. Foram entrevistados somente os produtores que aceitaram participar voluntariamente da pesquisa e que atendia o requesito mencionado anteriormente.

Os custos utilizados na análise econômica corresponderam aos dispêndios médios incorridos ao longo do horizonte de planejamentos dos plantios, referentes às atividades de implantação, colheita, carvoejamento e transporte da madeira pelos produtores, além do custo de aquisição da terra. Os custos relativos à manutenção dos povoamentos basearam-se em pesquisas na literatura e em sites especializados como: Embrapa Florestas e Centro de Desenvolvimento do Agronegócio (CEDAGRO).

Apresenta-se a seguir a discriminação dos custos referentes às atividades avaliadas por etapa do processo de produção da madeira:

$\checkmark$ Implantação: envolveu o preparo do solo, combate a pragas, controle de mato-competição, plantio, adubação, aquisição de mudas e insumos.

$\checkmark$ Anual da terra: referiu-se aos custos inerentes ao arrendamento da terra ou custo de oportunidade, ou seja, o que se deixa de ganhar pelo uso da terra como recurso próprio. 
$\checkmark$ Manutenção: correspondeu às despesas com operações inerentes à tratos culturais a partir do segundo ano de implantação do plantio, tais como: combate à formigas, adubações de cobertura, confecção e manutenção de aceiros, capina e, ou, roçada.

$\checkmark$ Condução de rebrota: gastos com a atividade de desbrota, após o primeiro corte raso da floresta. Na produção de madeira para serraria este ocorreu no $12^{\circ}$ ano e, nos demais usos da madeira, no $7^{\circ}$ ano.

$\checkmark$ Colheita: correspondeu aos custos com as operações de corte semimecanizado (motosserra) e extração de madeira com auxilio de caminhões, tratores e, em alguns casos, por meio de tração animal.

$\checkmark$ Colheita e carvoejamento: referiu-se às operações de corte e extração da madeira, transporte para carvoaria, enchimento dos fornos de carbonização e, posteriormente, a retirada do carvão. Salienta-se que os custos de colheita da madeira seguida de carvoejamento ocorreram apenas, para as situações que envolviam a produção de carvão vegetal.

$\checkmark$ Transporte: gastos com o deslocamento dos produtos florestais das propriedades rurais até a local de utilização/consumo.

Assim, foram entrevistados 15 produtores rurais que já haviam realizado o corte e a comercialização de madeira para quaisquer das quatro finalidades estabelecidas (madeira para produção de carvão, energia/lenha, construção civil e serraria), tendo sido utilizado o Microsoft Excel 2007 para tabular os dados e realizar as avaliações econômicas pertinentes.

\section{Avaliação econômica}

Realizou-se a análise econômica para cada uma das quatro opções de uso da madeira de eucalipto estabelecidas, considerando-se um horizonte de planejamento de 14 anos para a madeira destinada à produção de carvão vegetal, energia/lenha e para construção civil, efetuando-se o corte raso da floresta no sétimo ano, conduzindo a brotação e realizando outro corte, no décimo quarto ano. Para a madeira destinada a serraria adotou-se horizonte de planejamento de 24 anos, com prescrição de corte raso aos 12 e 24 anos.

Para os custos de produção considerou-se os valores médios obtidos perante os produtores rurais avaliados, com as receitas sendo obtidas mediante a multiplicação da produtividade dos plantios pelos preços de comercialização dos produtos praticados pelos produtores rurais na região. A produção final dos plantios no primeiro corte foi a real medida pelos próprios produtores e, o incremento do segundo ciclo foi estimado considerando decréscimo de $20 \%$ do total produzido no primeiro corte. A condução dos reflorestamentos foi pelo regime de talhadia (segundo ciclo de corte), não tendo sido realizado desbaste, por esta prática ser pouco utilizada na região. De posse dos dados de custos e receitas procedeu-se as análises de viabilidade econômica para cada uso da madeira estabelecido.

Nestas análises foram consideradas as três taxas de juros mais praticadas por instituições financeiras concessoras de crédito rural no Brasil, bem com as mais utilizadas para análise de sensibilidade de projetos florestais por diversos autores, a saber: de 6\%,9\% e 12\% ao ano (a.a). Assim, para estas taxas foram efetuadas simulações com a finalidade de verificar se a rentabilidade dos investimentos se manteria ou não.

$\mathrm{O}$ custo anual da terra para todos os casos foi determinado pela multiplicação das taxas de juros consideradas anteriormente, pelo valor médio da terra na região.

As fórmulas utilizadas para se verificar viabilidade econômica de uso da madeira de eucalipto para as quatro finalidades estabelecidas baseou-se na metodologia descrita por Rezende e Oliveira (2008), a saber:

Valor presente líquido - VPL

Corresponde à determinação da viabilidade econômica de um projeto pela diferença positiva entre benefícios e custos atualizados, de acordo com determinada taxa de desconto. O investimento torna-se economicamente viável se o VPL for positivo e, quanto maior o VPL, mais atrativo será o projeto.

$$
V P L=\sum_{j=0}^{n} R_{j}(1+i)^{-j}-\sum_{j=0}^{n} C_{j}(1+i)^{-j}
$$

em que: $V P L=$ valor presente líquido; $R j=$ receita no ano $j ; C j=$ custo no ano $j ; i=$ taxa de desconto; $j=$ período de ocorrência do custo, ou da receita; $n=$ duração do projeto, em anos.

Valor periódico equivalente - VPE

É a parcela periódica e constante necessária ao pagamento de uma quantia igual ao VPL da opção de investimento em análise, ao longo de sua vida útil. Um projeto será economicamente viável se apresentar VPE positivo. Quanto à seleção de projetos alternativos deve ser escolhido o que apresentar maior VPE para 
determinada taxa de desconto. A relevância deste critério esta na possibilidade de comparação de projetos com diferentes durações/horizonte de planejamento, uma vez que os valores equivalentes obtidos corrigem, implicitamente, essas diferenças de horizonte.

$$
V P E=\frac{V P L * i}{\left[1-(1+i)^{-n}\right]}
$$

em que: $V P E=$ valor periódico equivalente; $V P L=$ Valor Presente Líquido; $i=$ taxa de desconto; $n=$ duração do projeto, em anos.

Taxa interna de retorno - TIR

Corresponde a taxa de desconto que iguala o valor atual das receitas futuras, ao valor atual dos custos futuros. Ainda pode ser entendida como taxa média de aumento do investimento ao longo do tempo, com base nos recursos requeridos para produzir o fluxo de receitas. O projeto é economicamente viável se sua TIR for maior que a taxa de desconto correspondente à taxa de remuneração alternativa do capital, usualmente denominada de Taxa Mínima de Atratividade (TMA). Assim, o projeto que fornecer maior TIR será considerado o melhor, para projetos com mesma durabilidade e montante de investimento equivalente.

$$
T I R=\sum_{j=0}^{n} R_{j}(1+i)^{-j}=\sum_{j=0}^{n} C_{j}(1+i)^{-j}
$$

em que: $T I R=$ taxa interna de retorno; $R j=$ receita no ano $j ; C j=$ custo no ano $j ; i=$ taxa de desconto; $j=$ período de ocorrência do custo, ou da receita; $n=$ duração do projeto, em anos.

\section{Análise de sensibilidade}

Justifica-se esta análise por que a produtividade dos povoamentos é muito variável entre os produtores rurais, devido aos seguintes fatores: condições edafoclimáticas diversificadas, práticas de implantação e condução dos reflorestamentos variáveis, fatores intrínsecos a produção de mudas oriundas de sementes (REZENDE et al., 2006), material genético, incidência de pragas, doenças, entre outros. Além disso, os preços dos produtos florestais estão sujeitos a flutuações do mercado. Desta forma, tanto a produtividade dos plantios quanto o preço praticado na comercialização da produção florestal são determinantes na lucratividade de reflorestamentos de eucalipto.

Nesse sentido, a análise de sensibilidade tem sido muito utilizada atualmente para estudar o efeito das incertezas inerentes à produção e comercialização rural no decorrer do tempo, sob a renda dos produtores. Assim, a simulação de cenários com variação de fatores determinantes na produção florestal, bem como na viabilidade econômica dos reflorestamentos podem subsidiar a tomada de decisão sobre a melhor alternativa de uso da madeira, principalmente visando maiores retornos financeiros.

Portanto, após proceder às análises de viabilidade com base nos critérios econômicos estabelecidos, procurou-se variar em $10 \%$ para mais e para menos a produção florestal obtida $\left(\mathrm{m}^{3} / \mathrm{ha}\right)$ e, também, o preço dos quatro produtos florestais avaliados, a fim de se verificar o efeito destas mudanças no VPE das referidas atividades.

\section{RESULTADOS E DISCUSSÃO}

\section{Características das propriedades rurais e dos produtores}

As propriedades avaliadas têm em média 530,3 hectares (ha), variando entre 20 ha (menor área) e 3.800 ha (maior área).

Dos 15 produtores rurais entrevistados todos eram do sexo masculino. A idade média destes é de 47,7 anos, variando entre 28 a 70 anos, com $60,0 \%$ tendo nível de escolaridade correspondente ao ensino médio, $20,0 \%$ cursaram até o ensino fundamental, 13,3\% o ensino superior e 6,67\% o ensino técnico.

Quanto à ocupação e fonte de renda, 33,3\% trabalham somente em sua propriedade e, 66,7\% trabalham também em outro local, dos quais apenas $10 \%$ são assalariados e, os outros $90 \%$ são autônomos.

Portanto, segundo se constatou os reflorestamentos com eucalipto na região estudada representam fonte de renda extra para os produtores rurais, agregando receitas às atividades desenvolvidas em suas propriedades e, portanto, proporcionando melhoria da qualidade de vida de suas famílias.

Oliveira et al (2006), analisando aspectos de relevância econômica do fomento florestal a partir da percepção dos produtores rurais envolvidos, ressaltaram também a importância da silvicultura na composição da renda familiar destes, bem como a importância da atividade na viabilização de investimentos na propriedade, na aquisição de máquinas e equipamentos, no pagamento de dívidas, no lazer e educação de seus familiares, utilizando para tal as receitas provenientes da atividade. 
Assim, os resultados obtidos corroboram as conclusões obtidas por Oliveira et al (2006), ao constatar a importância da silvicultura como alternativa de diversificação de renda e incremento de receitas para pequenos e médios produtores rurais da região.

\section{Características das atividades desenvolvidas}

A eucaliptocultura foi responsável por parte do uso e ocupação do solo nas propriedades amostradas da região do Alto Jequitinhonha, sendo de fundamental importância na inserção de fatores produtivos em áreas degradadas e, ou, com baixa aptidão agrícola.

Todas as propriedades avaliadas apresentaram áreas ocupadas com o plantio de eucalipto, das quais $33,3 \%$ destas têm como única atividade produtiva, o reflorestamento. A área média reflorestada foi de 208,41 ha, variando entre cinco (5) e 1.200 ha, a área mínima e máxima ocupada com esta cultura, respectivamente.

Nas propriedades avaliadas são desenvolvidas também outras atividades agropecuárias como plantio do milho, alho, morango, café, hortaliças e pastagem para criação extensiva de gado, mas estas não foram mensuradas por serem destinadas principalmente ao consumo próprio e não, à comercialização.

O eucalipto é cultivado em $60,0 \%$ das propriedades, nas quais os produtores plantam de duas ou mais espécies deste gênero, particularmente o Eucalyptus cloesiana F. Muell que está presente em 73,3\% destas. Souza (2012), estudando a cultura do eucalipto no Alto Jequitinhonha considerando diferentes tecnologias de plantio menciona que, o Eucalyptus cloesiana corresponde a principal espécie plantada por produtores rurais da região, devido suas propriedades físico-mecânicas adequadas à produção de carvão, sua resistência, durabilidade, forma e cor, que favorece o emprego da madeira na construção civil.

Custos de produção

O custo médio para implantação de um hectare de eucalipto no Alto Vale do Jequitinhonha corresponde a $\mathrm{R} \$ 2.289,00 /$ ha, variando de $\mathrm{R} \$ 1.000,00$ a $\mathrm{R} \$ 5.000,00 / \mathrm{ha}$.

Tomando por base o custo médio de terra na região ( $\mathrm{R} \$ 2.315,00 / \mathrm{ha})$ e as taxas de juros estabelecidas $(6 \%, 9 \%$ e $12 \%$ a.a.) foram obtidos os seguintes valores de custos anuais da terra: $\mathrm{R} \$ 138,90 / \mathrm{ha} / \mathrm{ano}$, $\mathrm{R} \$ 208,35 /$ ha/ano e $\mathrm{R} \$ 277,80 /$ ha/ano, respectivamente.

$\mathrm{O}$ custo de manutenção correspondeu ao valor de $\mathrm{R} \$ 413,5 / \mathrm{ha} / \mathrm{ano}$ no segundo ano de plantio e, $\mathrm{R} \$ 161,75 /$ ha/ano nos demais períodos (a partir do $3^{\circ}$ ano), dentro do horizonte de planejamento dos projetos florestais estabelecidos.

O custo de condução de rebrota foi de $\mathrm{R} \$ 210,00 /$ ha para todos os projetos.

Assim, os custos de implantação, manutenção, condução de rebrota e custo da terra foram similares para todos os projetos analisados. Entretanto, os custos de colheita e de transporte variaram em função da produtividade dos plantios e uso da madeira (Tabela 1).

Tabela 1. Custos médios das atividades de colheita, carvoejamento, carregamento e transporte, para a produção de carvão vegetal, madeira em tora para energia e construção civil e, para serraria.

Table 1. Average costs of harvesting, charcoal production, loading and transportation, for the production of charcoal production, logs for energy, construction and sawmill.

\begin{tabular}{lccc}
\hline \multirow{2}{*}{ Operações Florestais } & Coeficiente Técnico & $\mathbf{1}^{\mathbf{0}}$ Ciclo & $\mathbf{2}^{\mathbf{0}}$ Ciclo \\
\cline { 2 - 4 } & $\left(\mathrm{R} \$ / \mathrm{m}^{\mathbf{3}}\right)$ & \multicolumn{2}{c}{ Carvão Vegetal } \\
\hline Colheita e carvoejamento & $38,62^{*}$ & $4.269,82$ & $3.415,93$ \\
Carregamento & $5,71^{*}$ & 631,29 & 505,04 \\
Transporte & $25,00^{*}$ & $2.764,00$ & $2.211,45$ \\
\hline Total & 69,33 & $7.665,11$ & $6.132,42$ \\
\hline & & Energia e Construção Civil \\
\hline Colheita & 6,61 & $1.131,03$ & 904,84 \\
Carregamento & 4,00 & 684,44 & 547,56 \\
Transporte & 10,00 & $1.711,10$ & $1.368,9$ \\
\hline Total & 20,61 & $3.526,57$ & $2.821,30$ \\
\hline & & & Serraria \\
\hline Colheita & 6,61 & $1.322,00$ & $1.057,60$ \\
Carregamento & 4,00 & 800,00 & 640,00 \\
Transporte & 10,00 & $2.000,00$ & $1.600,00$ \\
\hline Total & 20,61 & $4.122,00$ & $3.297,60$ \\
\hline
\end{tabular}

*R\$/Metro de carvão (mdc).

FLORESTA, Curitiba, PR, v. 46, n. 2, p. 155 - 164, abr. / jun. 2016.

Coelho, R. M. et al.

ISSN eletrônico 1982-4688

DOI: $10.5380 /$ rf.v46i2.38600 
O custo de transporte para o projeto de produção de carvão correspondeu a R $\$ 25,00 /$ metro (mdc). Considerando a capacidade de carga de um caminhão "truck" de 70 mdc (REZENDE et al., 2006), o custo total de transporte foi de $\mathrm{R} \$ 1.750,00$ por carga. Na atividade de carvoejamento considerou-se também o custo de confecção da carga correspondente a $\mathrm{R} \$ 400,00$. Para projetos de venda da madeira em tora (construção civil, energia e serraria), o custo de transporte correspondeu a R\$10,00/ $\mathrm{m}^{3}$. Dada a capacidade de carga de um caminhão "truck" de 30 metros estéreos (mst) de madeira e, considerando um fator de conversão volumétrico de estéreo para metro cúbico (de 1,5), o custo total de transporte correspondeu a R $\$ 200,00 /$ carga. Nos projetos de venda da madeira em tora o preço de carregamento do caminhão foi equivalente a $\mathrm{R} \$ 80,00$ por carga. A grande variação nos preços do transporte se deve a venda da madeira em tora ocorrer nas proximidades onde a mesma é produzida, em detrimento a comercialização de carvão, cujo destino final são pólos siderúrgicos de Minas Gerais (Sete Lagoas, João Monlevade e Divinópolis).

O custo total de produção para os diferentes usos da madeira de eucalipto, considerando duas rotações e excluindo o custo da terra, foi de a $\mathrm{R} \$ 18.648,25 / \mathrm{ha}$, $\mathrm{R} \$ 11.201,37 /$ ha e, $\mathrm{R} \$ 13.890,60 /$ ha respectivamente, para a produção de carvão vegetal, madeira para energia e construção civil e, para serraria. Maiores gastos/dispêndios foram observados no projeto destinado à produção de carvão vegetal, devido os processos de carbonização e transporte onerarem demasiadamente este processo. Os projetos de comercialização de madeira para energia e para construção civil apresentaram o mesmo valor de custo total ( $\mathrm{R} \$ 11.201,37 / \mathrm{ha})$. A produção de madeira destinada à serraria correspondeu a um maior valor de alocação de recursos para sua implantação/operacionalização, comparativamente a produção de madeira em tora para energia e construção civil. Isto se deve ao seu maior horizonte de planejamento (24 anos), consequentemente os custos com manutenção são maiores, comparativamente aos demais projetos.

Produção final e comercialização dos produtos

A produção volumétrica dos povoamentos de eucalipto ( $1^{\mathrm{a}}$ e $2^{\mathrm{a}}$ rotação), bem como o preço de comercialização da madeira para os diferentes usos estabelecidos na região do Alto Jequitinhonha são apresentados na tabela 2 .

Tabela 2. Produção volumétrica e preços de comercialização para os diferentes produtos/usos da madeira.

Table 2. Volume production and prices in the commercialization of the different forest products/wood uses.

\begin{tabular}{cccc}
\hline \multirow{2}{*}{ Uso da madeira } & \multicolumn{2}{c}{ Produção } & \multirow{2}{*}{ Preço $\left(\mathbf{R} \$ / \mathbf{m}^{3}\right)$} \\
\cline { 2 - 3 } & $1^{\mathrm{a}}$ rotação $\left(\mathrm{m}^{3} / \mathrm{ha}\right)$ & $2^{\mathrm{a}}$ rotação $\left(\mathrm{m}^{3} / \mathrm{ha}\right)$ & $148,0^{* *}$ \\
Carvão & $110,5^{*}$ & $88,4^{*}$ & 52,5 \\
Energia & 171,1 & 136,8 & 147,5 \\
Construção Civil & 171,1 & 136,8 & 170,0 \\
Serraria & 200,0 & 160,0 & \\
\hline
\end{tabular}

*Metros de carvão (mdc)/hectare (ha); **R \$/mdc.

A produção volumétrica final média dos plantios que destinaram a madeira em tora para energia e construção civil correspondeu a $171,11 \mathrm{~m}^{3} / \mathrm{ha}\left(1^{\circ}\right.$ ciclo), variando de $100-270 \mathrm{~m}^{3} / \mathrm{ha}$. O estoque volumétrico da madeira para serraria foi de $200 \mathrm{~m}^{3} / \mathrm{ha}$ aos 12 anos. O volume médio de carvão produzido ao final do primeiro ciclo correspondeu a 110,56 mdc/ha, variando de 100,00 - 150,00 mdc/ha. A produção de madeira em tora para energia e construção civil, de madeira em tora para serraria e de carvão vegetal no segundo ciclo correspondeu a $136,89 \mathrm{~m}^{3} / \mathrm{ha}, 160 \mathrm{~m}^{3} / \mathrm{ha}$ e $88,45 \mathrm{mdc} / \mathrm{ha}$, respectivamente (Tabela 2 ).

Guimarães et al. (2007), estimando a produtividade de reflorestamentos de eucalipto na região do Alto Jequitinhonha, em Minas Gerais, baseando nas características edafoclimáticas, fisiológicas e níveis tecnológicos empregados nos plantios encontraram produtividades entre 17 a $21 \mathrm{~m} 3 / \mathrm{ha} /$ ano para emprego de nível tecnológico médio, comumente utilizado por pequenos produtores rurais. Já quando adotado alto nível tecnológico e, tratos culturais comumente empregados por grandes empresas do setor de reflorestamento, a produção foi de 35 a $45 \mathrm{~m}^{3} / \mathrm{ha} / \mathrm{ano}$

A produtividade média dos plantios que destinaram a madeira para energia/lenha e serraria correspondeu a 24,4 e $16,6 \mathrm{~m}^{3} / \mathrm{ha} /$ ano, respectivamente. Ressalta-se que para o segundo ciclo/rotação adotou-se um decréscimo de $20 \%$ da produção $\left(19,5\right.$ e $\left.13,3 \mathrm{~m}^{3} / \mathrm{ha} / \mathrm{ano}\right)$ para os mesmos projetos, uma vez este valor percentual ser o mais adotado na literatura.

O baixo incremento volumétrico médio anual dos plantios de eucalipto avaliados representa uma realidade caracterizada por baixa tecnologia adotada na implantação dos reflorestamentos pela maioria dos produtores rurais no Alto Jequitinhonha. A deficiência de assistência técnica assim como, o pequeno investimento nos insumos básicos de produção constituem os principais fatores responsáveis pela baixa produtividade dos reflorestamentos. Por sua vez, isto mostra o grande potencial para melhorias, sobretudo com a difusão de novas técnicas e procedimentos de cultivo do eucalipto. 
O preço médio de comercialização da madeira em tora (aos sete anos) para energia e construção civil na região foi de $\mathrm{R} \$ 52,5 / \mathrm{m}^{3}$ e $\mathrm{R} \$ 147,5 / \mathrm{m}^{3}$, respectivamente. O preço médio de comercialização da madeira para serraria (aos 12 anos) foi de $\mathrm{R} \$ 170,00 / \mathrm{m}^{3}$ e, pelo Metro Cúbico de Carvão (MDC) foi de $\mathrm{R} \$ 148,00$.

Assim, a madeira para construção civil foi a que apresentou o maior preço médio $\left(\mathrm{R} \$ / \mathrm{m}^{3}\right)$, devido esta poder ser convertida em peças mais nobres como: caibros e linhas para telhado, taboas para móveis, moirões esquadrejados, entre outras finalidades.

\section{Análise econômica}

Entre as alternativas avaliadas a que proporcionou maior retorno financeiro correspondeu ao uso da madeira para construção civil, seguido da destinação desta para serraria, carvão vegetal e, por último, para energia. Ressalta-se que nas condições analisadas a produção de madeira para energia não se mostrou economicamente viável para as taxas de desconto de $9 \%$ e 12\% a.a., segundo os critérios VPL, VPE e TIR (Tabela 3). Para estas duas taxas de desconto a TIR encontrada apesar de positiva (5 e $2 \%$ a.a.), caracteriza inviabilidade desta alternativa, uma vez a TIR ser menor que TMA. Assim, os produtores que decidiram investir nesta opção perderam R $\$ 110,35$ e $\mathrm{R} \$ 262,01 /$ ha/ano, respectivamente.

Tabela 3. Análise econômica para as quatro alternativas de investimento, considerando-se três taxas de juros $(6 \%, 9 \%$ e $12 \%$ a a. $)$.

Table 3. Economic analysis for the four investment alternatives, considering three interest rates $(6 \%, 9 \%$ and $12 \%$ p.y.)

\begin{tabular}{|c|c|c|c|}
\hline Método de Avaliação & $6 \%$ & $9 \%$ & $12 \%$ \\
\hline & \multicolumn{3}{|c|}{ Carvão Vegetal } \\
\hline VPL (R\$/ha) & $3.702,78$ & $1.688,14$ & 258,89 \\
\hline VPE (R\$/ha.ano) & 398,36 & 216,81 & 39,06 \\
\hline \multirow[t]{2}{*}{$\operatorname{TIR}(\%)$} & 17,0 & 15,0 & 13,0 \\
\hline & \multicolumn{3}{|c|}{ Madeira para Energia } \\
\hline VPL (R\$/ha) & 402,66 & $-859,21$ & $-1.736,67$ \\
\hline VPE (R\$/ha.ano) & 43,32 & $-110,35$ & $-262,01$ \\
\hline \multirow[t]{2}{*}{$\operatorname{TIR}(\%)$} & 8,0 & 5,0 & 2,0 \\
\hline & \multicolumn{3}{|c|}{ Madeira para Construção Civil } \\
\hline VPL (R \$ha) & $16.965,38$ & $11.924,65$ & $8.277,46$ \\
\hline VPE (R\$/ha.ano) & $1.825,22$ & $1.531,52$ & $1.248,83$ \\
\hline \multirow[t]{2}{*}{$\operatorname{TIR}(\%)$} & 38,0 & 36,0 & 35,0 \\
\hline & \multicolumn{3}{|c|}{ Madeira para Serraria } \\
\hline VPL (R \$/ha) & $14.649,21$ & $7.819,63$ & $3.576,19$ \\
\hline VPE (R\$/ha.ano) & $1.167,23$ & 805,60 & 459,41 \\
\hline $\operatorname{TIR}(\%)$ & 21,0 & 20,0 & 18,0 \\
\hline
\end{tabular}

A produção de madeira para serraria e carvão vegetal mostram-se viáveis economicamente para as três taxas de juros empregadas (VPL positivo). Tendo em vista estas duas alternativas terem horizontes de planejamento diferentes verificou-se pelo VPE que, o uso da madeira para serraria mostrou-se mais rentável que a produção de carvão vegetal em $65 \%, 73 \%$ e $91 \%$, para as taxas de desconto de $6 \%$, $9 \%$ e $12 \%$ a.a., respectivamente.

Verificou-se também por intermédio do VPE que o uso da madeira para construção civil foi a melhor alternativa de investimento, para todas as taxas de juros consideradas. Pela TIR o retorno financeiro nesta alternativa foi de $38 \%, 36 \%$ e $35 \%$ a.a., correspondente às taxas de 6,9 e $12 \%$ a.a., respectivamente.

\section{Análise de Sensibilidade}

Buscou-se com esta avaliação verificar a influencia da variação da produtividade dos reflorestamentos e do preço de mercado da madeira nos resultados econômicos, utilizando o critério do Valor Periódico Equivalente (VPE), uma vez que este permite a comparação de projetos com diferentes horizontes de planejamento.

Efeito da produção florestal

De acordo com Guimarães et al. (2007), a produtividade dos reflorestamentos de eucalipto em propriedades no Alto Jequitinhonha varia de 17 a $21 \mathrm{~m}$ 3/ha/ano, utilizando-se nível de tecnologia médio, que é o processo comumentemente empregado por pequenos e médios produtores rurais. Desta forma, procuro-se variar a produção volumétrica média dos reflorestamentos em $10 \%$ para mais e para menos, a fim de avaliar o efeito desta variável na viabilidade ou não do investimento. 
Conforme tabela 4, verifica-se que a produção de madeira destinada a energia/lenha tornou-se inviável economicamente, com decréscimo da produtividade dos povoamentos em 10\%. Os VPE correspondentes a essa opção foram de - $\mathrm{R} \$ 16,64 / \mathrm{ha} / \mathrm{ano}$, - $\mathrm{R} \$ 165,59 / \mathrm{ha} /$ ano e - $\mathrm{R} \$ 312,83 / \mathrm{ha} /$ ano, para as taxas de juros de $6 \%$, $9 \%$ e $12 \%$. Por sua vez, neste mesmo cenário a produção de madeira destinada a carvão vegetal tornou-se inviável economicamente a uma taxa de desconto de apenas 12\% a.a. (VPE negativo de - R \$41,72/ha/ano).

Tabela 4. Efeito da variação da produção $\left(\mathrm{m}^{3} / \mathrm{ha}\right)$ dos plantios no VPE (R $\$ /$ ha.ano), para as taxas anuais de desconto de $6 \%, 9 \%$ e $12 \%$.

Table 4. Effect of variation in the production $\left(\mathrm{m}^{3} / \mathrm{ha}\right)$ in the plantations on EPV (R $\$ /$ ha.year), for annual discount rates of $6 \%, 9 \%$ and $12 \%$.

\begin{tabular}{cccccc}
\hline \multirow{2}{*}{ Produção } & \multirow{2}{*}{ Taxa $(\boldsymbol{\%})$} & \multicolumn{4}{c}{ VPE (R\$/ha/ano) } \\
\cline { 3 - 5 } & & Carvão & Energia & Construção Civil & Serraria \\
\hline \multirow{2}{*}{$-10 \%$} & 6 & 303,09 & $-16,64$ & $1.586,64$ & $1.001,89$ \\
& 12 & 129,02 & $-165,59$ & $1.311,74$ & 665,03 \\
& 6 & $-41,72$ & $-312,83$ & $1.046,63$ & 353,22 \\
\hline \multirow{2}{*}{ Real $^{*}$} & 9 & 398,36 & 43,32 & $1.825,22$ & $1.167,23$ \\
& 12 & 216,81 & $-110,35$ & $1.531,52$ & 805,60 \\
& 6 & 39,06 & $-262,01$ & $1.248,83$ & 459,41 \\
\hline \multirow{2}{*}{$+10 \%$} & 9 & 543,38 & 102,96 & $2.062,53$ & $1.332,58$ \\
& 12 & 344,79 & $-33,49$ & $1.812,14$ & 946,16 \\
\hline
\end{tabular}

Real* = Produção média dos reflorestamentos obtida pela aplicação do questionário aos produtores rurais

Mesmo com decréscimo de $10 \%$, a produção de madeira para serraria e para construção civil mostraram-se economicamente viáveis para todas as taxas de desconto empregadas, com a segunda opção apresentando maior retorno financeiro.

O uso da madeira para a produção de carvão vegetal e para energia, considerando as taxas de $12 \%$ e $6 \%$ respectivamente, foram as duas atividades que sofreram a maior influência da queda da produção florestal ($10 \%)$, em seu VPE.

O aumento da produção em $10 \%$ resultou em incremento no VPE de 36,40\% (madeira para carvão); 137,67\% (para lenha/energia); 13,00\% (para construção civil) e, 14,16\% (para serraria), a uma taxa anual de juros de $6 \%$.

Assim, a madeira destinada à construção civil apresentou retorno líquido 36,97\% maior que a venda desta para serraria, $81,05 \%$ que a destinada para produção de carvão vegetal e, 9.635,09\% superior ao uso desta para fins energéticos, considerando-se a taxa de $6 \%$ a.a. O maior preço pago pelo metro cúbico da madeira para construção civil (R $\$ 147,50)$, associado ao ciclo de corte desta também de sete anos, ajudam a explicar a superioridade de retorno financeiro desta atividade, comparativamente às demais alternativas de uso da madeira. Apesar de o preço médio pago pela madeira para serraria ter sido superior a todas as alternativas (de $\left.\mathrm{R} \$ 170,00 / \mathrm{m}^{3}\right)$, o ciclo de corte desta atividade foi de 12 anos, proporcionando menor VPE que a madeira destinada à construção civil.

Efeito do preço

Quando verificado a influência da variação do preço no VPE (10\% para mais e para menos), mais expressivos ainda foram os resultados obtidos (Tabela 5). Assim, considerando a taxa anual de desconto de 6\% a.a. e, queda de $10 \%$ no preço da madeira, as variações percentuais para menos no VPE corresponderam a: 45,01\% (madeira para carvão), 227,35\% (energia), 15,16\% (construção civil) e 16,12\% (serraria). Este percentual de redução no preço da madeira torna a queda do VPE mais acentuada ainda, quando se utiliza a taxa de $12 \%$ a.a., ou seja, de 389,2\% (carvão), 31,88\% (energia), 18,8\% (construção civil) e 26,68\% (serraria).

Nas condições estudadas, o uso da madeira para lenha/energia gera valores de VPE negativos para as taxas de juros de 9 e $12 \%$ a.a. e, portanto, inviabilidade desta atividade devido ao baixo preço pago por esta madeira $\left(\mathrm{R} \$ 52,50 / \mathrm{m}^{3}\right)$. O preço mínimo pago pelo metro cúbico $\left(\mathrm{m}^{3}\right)$ da madeira para lenha/energia a fim desta atividade não gerar prejuízo (VPE $=0$ ), deve ser de $\mathrm{R} \$ 58,88 \mathrm{~m}^{3}$ e $\mathrm{R} \$ 68,97 / \mathrm{m}^{3}$, para as taxas de juros de $9 \%$ e $12 \%$ a.a., respectivamente.

Cordeiro et al. (2010b), estudando o efeito da elasticidade das variáveis preço, produtividade, taxa de juros, custo de colheita e implantação sobre o VPL de projetos florestais destinados a produção de carvão e madeira para celulose, afirmam que o preço e produtividade são nesta ordem, componentes de maior importância na viabilidade financeira destes projetos. Ainda, segundo os mesmos autores, o preço e a produtividade possuem relação direta com o VPL, ou seja, o incremento nestes, resulta em um maior retorno financeiro. 
Tabela 5. Efeito da variação do preço dos produtos madeireiros no VPE (R $\$ / h a / a n o)$, para diferentes taxas anuais de desconto $(6 \%, 9 \%$ e $12 \%)$.

Table 5. Effect of variation in the price of timber products on EPV (R $\$ /$ ha/year), for different annual discount rates $(6 \%, 9 \%$ and $12 \%)$.

\begin{tabular}{cccccc}
\hline \multirow{2}{*}{ Preço } & \multirow{2}{*}{ Taxa $(\%)$} & \multicolumn{4}{c}{ VPE $(\mathbf{R} \mathbf{\text { ha/ano } )}$} \\
\cline { 3 - 6 } & & Carvão & Energia & Construção Civil & Serraria \\
\hline \multirow{2}{*}{$-10 \%$} & 6 & 219,08 & $-55,17$ & $1.548,48$ & 979,07 \\
& 9 & 51,62 & $-201,10$ & $1.276,52$ & 645,64 \\
& 12 & $-112,96$ & $-345,53$ & $1.014,18$ & 336,84 \\
\hline \multirow{2}{*}{ Real ${ }^{*}$} & 6 & 398,36 & 43,32 & $1.825,22$ & $1.167,23$ \\
& 9 & 216,81 & $-110,35$ & $1.531,52$ & 805,60 \\
& 12 & 39,06 & $-262,01$ & $1.248,83$ & 459,41 \\
\hline & 6 & 577,75 & 141,77 & $2.101,78$ & 1355,39 \\
& 9 & 382,11 & $-19,64$ & $1.786,34$ & 965,56 \\
& 12 & 191,16 & $-178,54$ & $1.483,31$ & 607,10 \\
\hline
\end{tabular}

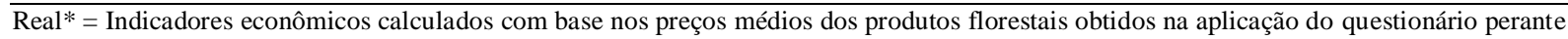
aos produtores rurais no Alto Jequitinhonha.

\section{CONCLUSÕES}

- Entre as alternativas de investimento avaliadas, a produção de madeira para construção civil foi a que apresentou melhor retorno econômico, seguida pela produção de madeira em tora para serraria.

- O aumento na taxa anual de juros apresentou relação inversa com o resultado dos indicadores econômicos (VPL, VPE e TIR) e, portanto, quanto menor a taxa de juros, maior a lucratividade dos investimentos.

- Apenas a destinação da madeira para energia/lenha proporcionou inviabilidade econômica do investimento, para as taxas de desconto de 9 e $12 \%$ a.a.

- A variação para mais e para menos no preço da madeira influenciou em maior grau o VPE dos investimentos, comparativamente ao aumento e redução da produtividade dos plantios.

- A produção de madeira advinda dos reflorestamentos com eucalipto na região do Alto Jequitinhonha constitui alternativa viável para diversificação da renda, absorção de mão de obra e, melhoria da qualidade de vida dos produtores rurais.

\section{AGRADECIMENTOS}

Ao Conselho Nacional de Desenvolvimento Científico e Tecnológico (CNPq) pelo apoio financeiro e, a Universidade Federal dos Vales do Jequitinhonha e Mucuri (UFVJM) pela infraestrutura concedida.

\section{REFERENCIAS}

BRASIL. Ministério do Planejamento e Orçamento. Fundação Instituto Brasileiro de Geografia e Estatística IBGE. Diagnóstico Ambiental da Bacia do Rio Jequitinhonha: Diretrizes Gerais para a Ordenação Territorial. Salvador, BA, 1997. 64 p.

CALIXTO, J. S.; RIBEIRO, E. M.; GALIZONI, F. M.; MACEDO, R. L. G. Trabalho, terra e geração de renda em três décadas de reflorestamento no Alto Jequitinhonha. Rev. Econ. Sociol., Piracicaba, v. 7, n. 2, p. 519 538, 2009.

CALIXTO, J. S.; RIBEIRO, A. E. M. Três olhares sobre o reflorestamento: a percepção de atores sociais sobre a monocultura de eucalipto no Alto Jequitinhonha, MG. Organizações Rurais \& Agroindustriais, Lavras, v. 9, n. 3, p. 437 - 450, 2007.

CANTO, J. L.; COELHO, F. M. G.; NOCE, R.; MACHADO, C. C.; REZENDE, J. L. P.; MENDES, L. M.; OLIVEIRA, J. M.; CORDEIRO, S. A.; SILVA, M. S.; JACOVINE, L. A. G.; VALVERDE, S. R.; SOARES, N. S. Aspectos Sociais do Fomento Florestal no Estado do Espírito Santo. Revista Cerne, Lavras, v. 15, n. 2, p. 123 - 132, 2009.

CHAVES, L. A.; RIBEIRO, L. G. G. Os atos ilícitos praticados no âmbito do reflorestamento no norte de Minas Gerais e Alto Jequitinhonha: estudo de caso e repercussão penal. Veredas do Direito, Belo Horizonte, v. 11, n. 21, p. 317 - 339, 2014. 
CENTRO DE DESENVOLVIMENTO DO AGRONEGÓCIO (CEDAGRO). Coeficientes técnicos e custos de produção na agricultura do Espírito Santo - Eucalipto. Disponível em: <http://www.cedagro.org.br/?page=pg coeficientes_planilhas $>$. Acesso em: 23/08/2011.

CORDEIRO, S. A.; SILVA, M. L.; JACOVINE, L. A. G.; VALVERDE, R. V. SOARES, N. S. Contribuição do fomento do órgão florestal de minas gerais na lucratividade e na redução de riscos para produtores rurais. Revista Árvore, Viçosa, v. 34, n. 2, p. 367 - 376, 2010.

EMBRAPA FLORESTAS. Produtos e Serviços - Planilha de custos de eucalipto. Disponível em: 〈http://www.cnpf.embrapa.br/publica/circtec/edicoes/circ-tec37.pdf〉. Acesso em: 23/08/2011.

GUIMARÃES, D. P.; SILVA, G. G. C.; SANS, L. M. A. S.; LEITE, F. P. Uso do modelo de crescimento 3-PG para o zoneamento do potencial produtivo do eucalipto no estado de Minas Gerais. Revista Brasileira de Agrometeorologia, v. 15, p. 192 - 197, 2007.

OLIVEIRA, P. R. S.; VALVERDE, S. R.; COELHO, F. M. G. Aspectos de relevância do fomento florestal a partir da percepção dos produtores rurais envolvidos. Revista Árvore, Viçosa, v. 30, n. 4, p. 593 - 601, 2006.

REZENDE, J. L. P.; OLIVEIRA, A. D. Análise econômica e social de projetos florestais. Viçosa, MG: Universidade Federal de Viçosa, 2001. 389 p.

REZENDE, J. L. P.; PADUA, C. T. G.; OLIEIRA, A. D.; SCOLFORO, J. R. S. Análise econômica de fomento florestal com eucalipto no estado de minas gerais. Revista Cerne, Lavras, v. 12, n. 3, p. 221 - 231, 2006.

SOUZA, A. P. Produção de madeira de eucalipto em propriedades rurais no Alto Jequitinhonha - MG. 76 f. Dissertação (Mestrado Ciência Florestal) - Universidade Federal dos Vales do Jequitinhonha e Mucuri, Diamantina, MG, 2012.

SOUZA, A. P.; SANTANA, R. C.; GILCIANO, S. N.; LEITE, A. M. P.; OLIVEIRA. M. R. L.; HENRIQUES, E. P. Silvicultura e produção de biomassa em propriedades rurais no Alto Jequitinhonha - MG. Biomassa \& Energia, Viçosa, v. 5, n. 1, p. 59 - 66, 2012.

SOUZA, U. R.; SILVA, F. L.; GRIFFITH, J. J.; LIMA, J. E.; QUINTELA, M. C. A.; COSTA, E. C. V. Determinantes dos novos contratos de fomento florestal na mesorregião do Vale do Rio Doce, Minas Gerais. Revista Árvore, Viçosa, v. 33, n. 2, p. 377 - 386, 2009. 